\title{
Essential Emergency Surgical Care in Remote Hilly Districts of Karnali - A Cross-Sectional Survey
}

\author{
*Praveen Kumar Giri ${ }^{1}$, Prem Prasad Panta ${ }^{2}$, Niresh Thapa ${ }^{3}$ \\ ${ }^{1}$ Assistant Professor, Department of Anesthesiology and Critical Care, ${ }^{2}$ Associate Professor, Department of \\ Public Health, ${ }^{3}$ Niresh Thapa, Associate professor, Department of Emergency Medicine, Karnali Academy \\ of Health Sciences, Jumla
}

*Corresponding Author: Dr. Praveen Kumar Giri, Email: giripkmd@gmail.com

\section{ABSTRACT}

Background: Remote hilly areas of Karnali Province has one in all the very best burdens of surgically treatable conditions within the world and therefore, the highest unmet need. The first objective of our study was to gauge the capacity of first-referral health facilities in remote districts of Karnali Province to perform basic surgical procedures. The aim is to assess the status of Essential Emergency Surgical Care in remote hilly districts of Karnali region of Nepal.

Method: The screening Tool was Situational Analysis to Assess Emergency and Essential Surgical Care, to spot the health facility's capacity to perform basic surgical (including obstetrics and trauma) and anesthetic procedures by investigating four categories of data: human resources, infrastructure, equipment and interventions available. The tool interrogated the supply of eight sorts of care providers, 35 surgical interventions and 67 items of apparatus.

Results: on the average, $72.83 \%$ of all admissions required either minor or major surgical interventions. Oxygen supplies, electrical power backup, running water, blood bank, hospital guidelines were inconsistent. Only 1 Hospital have trained Surgeons, Anesthesiologist and Obstetrician/Gynecologist. Only 1 hospital can perform around $97.1 \%$ of procedures.

Conclusion: The capacity for essential surgery is severely limited in Karnali region of Nepal. Limitations was seen in basic equipment, human resources, infrastructure, and supplies.

Keywords: Surgical Care, Emergency, Nepal.

\begin{tabular}{|l|l|l|}
\hline \multicolumn{2}{|c|}{ Access this article Online } & \multicolumn{1}{c|}{ Article Info. } \\
\hline Quick Response Code & \multicolumn{1}{|c|}{ Website: } & \multicolumn{1}{c|}{ How to cite this article in Vancouver Style? } \\
\hline & www.jkahs.org.np & $\begin{array}{l}\text { Giri PK, Panta PP, Thapa N. The Essential Emergen- } \\
\text { cy Surgical Care in remote hilly districts of Karnali } \\
\text { Province - A Cross-Sectional Survey. Journal of Kar- } \\
\text { nali Academy of Health Sciences 2020;3(2): 116-121 }\end{array}$ \\
\cline { 2 - 3 } & $\begin{array}{l}\text { Received } \\
\text { Accepted } \quad: \text { : } 2 \text { June 2020 } \\
\text { Published Online : }: 9 \text { August 2020 } \\
\text { https://doi.org/10.3126/ } \\
\text { jkahs.v3i2.31384 }\end{array}$ & $\begin{array}{l}\text { Conflict of Interest : None } \\
\text { Source of Support : None }\end{array}$ \\
\hline
\end{tabular}




\section{INTRODUCTION}

Diseases that can be treated with surgery estimated $11 \%{ }^{1}$. Despite recent data estimating the global volume of surgery at large number of surgical procedures annually and significant disparities among procedures performed in high-income and lowincome countries, worldwide public health initiatives have usually neglected the necessity for the provision of surgical services ${ }^{2}$.

Restricted access to surgical services, particularly at rural facilities, results in undesirable morbidity and mortality from a broad range of treatable surgical conditions including traumatic injuries, sequelae of infectious diseases, complications of pregnancy, acute abdominal conditions and congenital abnormalities ${ }^{3}$. Improving access to surgical services in low-income countries requires improvement in infrastructure, training and skills of health workers, appropriate management of equipment and medications. Enough surgical care is lacking in many low- and middleincome countries because of various barriers preventing patients from reaching the provider ${ }^{4}$.

Nepal is a country having a population of 29.3 million and a low Human Development Index ${ }^{5}$. At least 2.4 million individuals do not have access to needed surgical care in Nepal during their lifetimes, with those not accessing health facilities being lower literacy rates and fewer transport resources ${ }^{6}$. Limited access to all-weather roads accessibility to healthcare facilities for a large proportion of the Nepalese population is restricted.

The province occupies higher mountain land of north and mid-hills of Nepal. Injuries and accidents contributed $9 \%$ among other surgical conditions? The province are the districts with having very low human development index. All the health indicators are lower compared to other provinces .Demographic, socio-economic and transport-related characteristics that are associated with reduced surgical care in these regions ${ }^{8}$. Our study aimed to describe the main reasons why surgical care is not available in remote districts of Karnali province.

\section{MATERIALS AND METHODS}

This was a cross-sectional study, conducted in Karnali province of Nepal in 2017. Permission to collect the data was taken from respective hospital chief. The WHO Tool for Situational Analysis to Assess Emergency andEssentialSurgicalCare(EESC) ${ }^{9,10}$ was used to capture a health facility's capacity to perform basic surgical (including obstetrics and trauma) and anesthesia interventions by investigating four categories of data: human resources, infrastructure, equipment availability and interventions provided . The tool queried the availability of eight types of care providers, thirty five surgical interventions and sixty seven items of equipment. Five facilities (Dolpa, Humla, Mugu, Kalikot, and Jumla) situated in hilly districts of Karnali province were surveyed for the size of the 'population served', intending to quantify the population living in the catchment area. This assessment represents the number of residents who might use the facility as their first referral health facility, not the number of patients seen. Data were calculated using Excel software.

\section{RESULTS}

Five facilities, representing 5 districts and serving 429720 residents, completed the WHO Integrated Management for Emergency and Essential Surgical Care (IMEESC) Situational Analysis research tool. A total of 160 hospital beds were reported. Nine operating rooms were identified. The mean distance need to travel before admission was $50 \mathrm{~km}$. Annual average admission was 1188 per facility. On average, $73 \%$ of all admissions required either minor or major surgical interventions (Table 1)

Table 1: General information of 5 Health facilities in Karnali

\begin{tabular}{|c|c|c|c|c|c|c|c|c|c|}
\hline District & PC(n) & BA (n) & $\mathbf{A A}(\mathbf{n})$ & $\mathbf{A O}(\mathrm{n})$ & OR(n) & $\operatorname{ASP}(n)$ & $\operatorname{APS}(\mathbf{n})$ & $\operatorname{ARS}(n)$ & DTS(n) \\
\hline Dolpa & 40000 & 15 & 513 & 30364 & 1 & 1000 & 200 & 50 & NA \\
\hline Humla & 55720 & 15 & 540 & 28960 & 1 & 1300 & 490 & 95 & NA \\
\hline Mugu & 64000 & 15 & 960 & 24000 & 2 & 614 & 300 & 130 & 300 \\
\hline
\end{tabular}




\begin{tabular}{|l|l|l|l|l|l|l|l|l|l|}
\hline Kalikot & 150000 & 15 & 1500 & 17000 & 2 & 1000 & 500 & 100 & 200 \\
\hline Jumla & 120000 & 100 & 2429 & 24826 & 3 & 414 & 150 & 114 & 300 \\
\hline Total & 429720 & 160 & 5942 & 125150 & 9 & 4328 & 1640 & 489 & \\
\hline Mean & 85944 & 32 & 1188 & 25030 & 1.8 & 865 & 328 & 97.8 & \\
\hline
\end{tabular}

$\mathrm{NA}=$ not available, $\mathrm{PC}=$ Population Coverage, $\mathrm{BA}=$ Beds Available, $\mathrm{AA}=$ Annual Admission, $\mathrm{AO}=$ Annual Outpatients, $\mathrm{OR}=$ Operation Room, $\mathrm{ASP}=$ Annual Surgical Procedures , Annual pediatric surgery , ARS= Annual Refer Out for surgery, DTS= Distance Travel for Surgery

Oxygen supplies were inconsistent, four hospitals $(80 \%)$ had interrupted access to oxygen, with most relying on oxygen concentrators. Three $(60 \%)$ hospitals have available running water facilities, one $(20 \%)$ have limited running water facility and there was no running water facility in one (20\%) hospital. Four hospitals $(80 \%)$ had interrupted the electrical facility available, one (20\%) have inconsistent electric service where there was no alternative power backup in four (80\%) hospital and one (20\%) hospital had electrical back up. Three hospitals reported to have a blood bank. Four hospitals had facility to test hemoglobin and urine analysis. The x-ray was fully functional in all hospitals. There was no medical recording system in three hospitals. Four hospitals $(80 \%)$ had pulse oximeters. All hospitals $(100 \%)$ had an area designated for postoperative care. Two (40\%) hospitals had management guidelines for emergency care and only (20\%) one hospital had management guidelines for surgery, anesthesia and pain relief. Four hospitals $(80 \%)$ had no anesthesia machine (Table 2).

Table 2: Available infrastructure and other resources in 5 health facilities $(\mathrm{N}=5)$

\begin{tabular}{|l|l|l|l|}
\hline \multicolumn{2}{|c}{ Infrastructure and resources } & \multicolumn{2}{c}{$\begin{array}{c}\text { Available for } \\
\text { Sometimes (n) }\end{array}$} \\
\hline Oxygen cylinder & 4 & 0 & 1 \\
\hline Running water & 3 & 1 & 1 \\
\hline Electricity source & 4 & 1 & 0 \\
\hline Operational power generator & 1 & 0 & 4 \\
\hline Blood bank & 3 & 0 & 2 \\
\hline Hemoglobin and urine testing & 4 & 0 & 1 \\
\hline X-ray machine & 5 & 0 & 0 \\
\hline Medical records & 2 & 0 & 3 \\
\hline Pulse Oximeter & 4 & 0 & 1 \\
\hline Area designated for postoperative care & 5 & 0 & 0 \\
\hline Management guidelines for emergency care & 2 & 0 & 3 \\
\hline Management guidelines for surgery & 1 & 0 & 4 \\
\hline Management guidelines for anesthesia & 1 & 0 & 4 \\
\hline Management guidelines for pain relief & 1 & 0 & 4 \\
\hline Functioning anesthesia machine & 1 & 0 & 4 \\
\hline
\end{tabular}

Table 3 shows that there was only one facility, where trained Surgeons, Anesthesiologists and Obstetrician/ Gynecologists were available. Other 4 facilities didn't have such human resources. All the staffs working in those hospitals were full time, there were no part-time staffs. 
Table 3: Availability of human resources in 5 health facilities.

\begin{tabular}{|l|l|l|l|l|l|l|l|l|l|l|}
\hline & \multicolumn{3}{c}{ Dolpa } & \multicolumn{4}{c}{ Humla } & \multicolumn{3}{c|}{ Kugu } \\
& Full & Part & Full & Part & Full & Part & Full & Part & Full & Part \\
\hline Surgeons & 0 & 0 & 0 & 0 & 0 & 0 & 0 & 0 & 3 & 0 \\
\hline Anesthesiologist & 0 & 0 & 0 & 0 & 0 & 0 & 0 & 0 & 3 & 0 \\
\hline Obstetrician/Gynecologist & 0 & 0 & 0 & 0 & 0 & 0 & 0 & 0 & 2 & 0 \\
\hline General doctors providing surgery & 1 & 0 & 1 & 0 & 1 & 0 & 1 & 0 & 2 & 0 \\
\hline General doctors providing anesthesia & 0 & 0 & 0 & 0 & 0 & 0 & 0 & 0 & 2 & 0 \\
\hline Nurses /paramedics providing anesthesia & 0 & 0 & 1 & 0 & 1 & 0 & 1 & 0 & 2 & 0 \\
\hline Clinical officers providing surgery & 0 & 0 & 0 & 0 & 0 & 0 & 2 & 0 & 2 & 0 \\
\hline Paramedics/ Midwives providing surgery & 0 & 0 & 0 & 0 & 0 & 0 & 0 & 0 & 0 & 0 \\
\hline
\end{tabular}

Table 4 presents that of the 35 basic interventions listed in the tool, only minor procedure like suturing was available at all facilities. Additionally, only one hospital had performed around $97.1 \%$ of procedures. Four of the other hospitals- Dolpa( 64.7\%), Humla (44.1\%), Mugu (61.8\%) and Kalikot (44.1\%) did not have performed interventions. Referral rate of Dolpa, Humla, Mugu, Kalikot and Jumla hospitals were $67.4 \%, 50 \%, 61.8 \%, 47.1 \%$ and $2.9 \%$ respectively.

\section{Table 4: Status of intervention, referral, skilled human resource, equipment and supply}

\begin{tabular}{|c|c|c|c|c|c|c|}
\hline \multicolumn{2}{|c|}{ Particulars } & Dolpa & Humla & Mugu & Kalikot & Jumla \\
\hline Intervention & & & & & & \\
\hline & Performed & $12(35.3 \%)$ & $19(55.9 \%)$ & $13(38.2 \%)$ & $19(55.9 \%)$ & $33(97.1 \%)$ \\
\hline & Not performed & $22(64.7 \%)$ & $15(44.1 \%)$ & $21(61.8 \%)$ & $15(44.1 \%)$ & $1(2.9 \%)$ \\
\hline \multicolumn{7}{|l|}{ Referral } \\
\hline & No & $11(32.4 \%)$ & $17(50 \%)$ & $13(38.2 \%)$ & $18(52.9 \%)$ & $33(97.1 \%)$ \\
\hline & Yes & $23(67.6 \%)$ & $17(50 \%)$ & $21(61.8 \%)$ & $16(47.1 \%)$ & $1(2.9 \%)$ \\
\hline \multicolumn{7}{|c|}{ Lack of Skilled Human Resource } \\
\hline & No & $12(35.3 \%)$ & $21(61.8 \%)$ & $13(38.2 \%)$ & $18(52.9 \%)$ & $33(97.1 \%)$ \\
\hline & Yes & $22(64.7 \%)$ & $13(38.2 \%)$ & $21(61.8 \%)$ & $16(47.1 \%)$ & $1(2.9 \%)$ \\
\hline \multicolumn{7}{|c|}{ Available Equipment's } \\
\hline & Functioning & $34(100 \%)$ & $30(88.2 \%)$ & $34(100 \%)$ & $33(97.1 \%)$ & $34(100 \%)$ \\
\hline & Non Functioning & $0(0 \%)$ & $4(11.8 \%)$ & $0(0 \%)$ & $1(2.9 \%)$ & $0(0 \%)$ \\
\hline \multicolumn{7}{|c|}{ Hospital Supply } \\
\hline & Yes & $34(100 \%)$ & $34(100 \%)$ & $34(100 \%)$ & $31(91.2 \%)$ & $34(100 \%)$ \\
\hline & No & $0(0 \%)$ & $0(0 \%)$ & $0(0 \%)$ & $3(8.8 \%)$ & $0(0 \%)$ \\
\hline
\end{tabular}

\section{DISCUSSION}

This study is a preliminary but reliable evaluation and snapshot about the capacity of the Nepal health system to guarantee essential and emergency surgical care in the remote areas like Karnali Province. Our data show a remarkable shortcoming of available surgical care. The number of surgical beds is very
There was lack of skilled human resource in Dolpa (64.7\%), Humla (38.2\%), Mugu (61.8\%), Kalikot (47.1\%), and Jumla (2.9\%). Provided data shows that equipment and supply are adequate in all. Four hospitals had $100 \%$ supply and one had $91 \%$ supply. Three hospitals had all equipment functioning (100\%) and the other two hospitals had $2.9 \%$ and $11.8 \%$ nonfunctioning equipment. 
Emergency and essential surgical care needs are increasing worldwide, especially in low- and middleincome countries like Nepal and this fact are consistent with the growing volume of injuries, accounting for a large amount of the disease burden ${ }^{11}$. This growth often is unappreciated but brings as a consequence a great need for public-health efforts to improve the monitoring, safety, and availability of surgical and anesthesia services. The disproportionate scarcity of surgical procedures access in low-income and remote settings suggests a large unaddressed disease burden. Which is consistent with our study. The health status indicators of Karnali are among the worst in the country, which is not surprising considering difficult geographical distribution, poverty, literacy status, lack of access to other parts of the country, widespread hunger and malnutrition, increasing difficulty to provide aid by the central government. It is necessary to address the basic surgical capacity strengthening with a comprehensive integrated approach.

The scarcity of surgical beds is further identified by the increased surgical needs gives an explanation of the distances often required to be covered to obtain even basic surgical treatment. It may have a definite impact on the high maternal mortality rate of the country and on the poor clinical outcome of the newborn, which frequently require referral to a higher level of care. Moreover, usually, patients are referred to the hospitals by airplane. Ambulance services are not effective in these regions due to poor road condition and some districts are still untouched by motorable road, therefore unpredictable airplane is the only means of transportation. Basic amenities, such as running water, oxygen supply, and electricity are inconsistently available in most of the hospitals, making basic surgical interventions difficult.

Properly functioning anesthesia equipment are needed in peripheral hospitals. Surgical care includes the lack of experienced anesthesiology personnel , safe anesthetic equipment and having anesthesia services in place is one of the most urgent constraints shown by this study and results in the time-consuming referral to other facilities, use of inappropriate anesthetic techniques with a possible higher rate of complications and death. The shortage of qualified medical personnel is evident. Lifesaving procedures, such as cricothyroidotomy or chest tube insertion are rarely performed in many health facilities. Consistent with our study Contini et al. in 2010 conducted a survey in Afghanistan and they found that there was poor facility of, oxygen supply, continuous running water and electrical power. Moreover, they find that limited access to surgery is highly remarkable problem in Afghanistan, with a severe shortage of emergency surgical capacities in provincial and district hospitals, where availability of basic and emergency surgical care is far from satisfactory. ${ }^{12}$ Similarly, , Iddress et al. conducted a survey in the Gambia and Cohen et al. in Tanzania concluded that major gaps exist in the physical and human resources needed to carry out basic life-saving surgical interventions. ${ }^{13,14}$

This preliminary evaluation has some evident limitations. The number of facilities analyzed and the data is small; therefore, they may be skewed and may not give a comprehensive picture of the availability of emergency and essential surgical care in the whole country. The increasingly difficult geographical distribution, the long time to answer, sometimes the difficulty to obtain authorization to fulfill the questionnaire, etc., might underline how challenges could have been any attempt to obtain a larger sample of facilities and a more comprehensive evaluation. However, the health facilities surveyed are spread throughout the remote hilly areas of Karnali province; more peripheral health facilities show homogeneous features within the groups, and they are rather consistent in assuring basic and emergency surgical care.

\section{CONCLUSION}

Essential surgery is severely limited and unevenly provided due to poor physical infrastructure, lack of skilled human resources, and anesthesia equipment. We recommend further studies to elaborate on the surgical burden in all districts of Karnali Province.

\section{REFERENCE:}

1. Disease Control Priorities in Developing Countries (2nd Edition). 2006 https://doi. org/10.1596/978-0-8213-6179-5 [Google Scholar] [PubMed] [MC] 
2. Weiser TG, Regenbogen SE, Thompson KD, Haynes AB, Lipsitz SR, Berry WR et al. An estimation of the global volume of surgery: a modelling strategy based on available data. The Lancet 2008; 372-9633: 139-144. [Google Scholar] [PubMed] [Full Text]

3. Elkheir N, Sharma A, Cherian M, Saleh OA, Everard M, Popal GR et al. A cross-sectional survey of essential surgical capacity in Somalia. BMJ Open 2014:4-5 https://doi.org/10.1136/ bmjopen-2013-004360 [Google Scholar] [PubMed] [PMC] [Full Text]

4. Grimes CE, Bowman $\mathrm{KG}$, Dodgion $\mathrm{CM}$, Lavy CBD. Systematic review of barriers to surgical care in low-income and middle-income countries. World Journal of Surgery 2011; 355: 941-950. [Google Scholar] [PubMed] [․ㅏll Text]

5. UNFPA. Population Situation Analysis of Nepal. Unfpa Nepal 2017; : 1-3,6. Google Scholar, Full Text

6. Boeck MA, Nagarajan N, Gupta S, Varadaraj V, Groen RS, Shrestha S et al. Assessing access to surgical care in Nepal via a crosssectional, countrywide survey. Surgery (United States) 2016:160-2:501-508 doi:10.1016/j. surg.2016.03.012.Google Scholar, PubMed, Full Text

7. Organization WH. INJURIES VIOLENCE THE FACTS The magnitude and causes of injuries. 2014; : 20. Google Scholar, Full Text

8. van Loenhout JAF, Delbiso TD, Gupta S, Amatya K, Kushner AL, Gil Cuesta $\mathrm{J}$ et al. Barriers to surgical care in Nepal. BMC Health Services Research 2017. https://doi.org/10.1136/ bmjopen-2013-00436010.1186/s12913-0172024-7 [Google Scholar] [PubMed] [PMC] [Full Text]

9. Who. Tool for Situational Analysis to Assess Emergency and Essential Surgical Care Section A : Infrastructure Section B : Human Resources Section C : Interventions. [Full Text] [Google Scholar]
10. Choo S, Perry H, Hesse AAJ, Abantanga F, Sory E, Osen $\mathrm{H}$ et al. Assessment of capacity for surgery, obstetrics and anaesthesia in 17 Ghanaian hospitals using a WHO assessment tool. Tropical Medicine and International Health 2010 https://doi.org/10.1111/j.13653156.2010.02589.x [Google Scholar] [PubMed] [Full Text]

11. Kingdom U. Health Care Systems in Low- and Middle- Income Countries. 2014; 370: 552557. [Google Scholar] [ Full Text]

12. Contini S, Taqdeer A, Cherian M, Shokohmand AS, Gosselin R, Graaff P et al. Emergency and essential surgical services in afghanistan: Still a missing challenge. World Journal of Surgery 2010. https://doi.org/10.1007/s00268-0100406-7 [Google Scholar] [PubMed] [Full Text]

13. Iddriss A, Shivute N, Bickler S, Cole-Ceesay R, Jargo B, Abdullah F etal. Emergency, anaesthetic and essential surgical capacity in the Gambia. Bulletin of the World Health Organization 2011. https:doi.org/10.2471/blt.11.086892 [Google Scholar] [PubMed] [PMC] [Full Text]

14. Penoyar T, Cohen H, Kibatala P, Magoda A, Saguti G, Noel L et al. Emergency and surgery services of primary hospitals in the United Republic of Tanzania. BMJ Open 2012:2-1:e000369 https://doi.org/10.1136/ bmjopen-2011-000369 [Google Scholar] [PubMed] [PMC] [Full Text] 